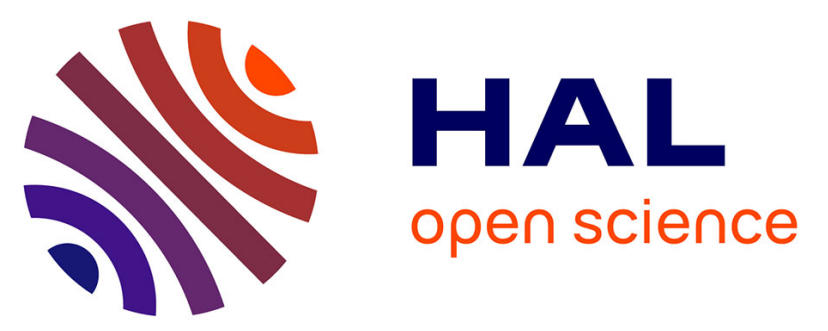

\title{
Poly( $\epsilon$-caprolactone)/Hydroxyapatite 3D Honeycomb Scaffolds for a Cellular Microenvironment Adapted to Maxillofacial Bone Reconstruction
}

Alejandro Garcia Garcia, Anne Hebraud, Jean-Luc Duval, Corinne Wittmer, Ludovic Gaut, Delphine Duprez, Christophe Egles, Fahmi Bedoui, Guy Schlatter, Cécile Legallais

\section{To cite this version:}

Alejandro Garcia Garcia, Anne Hebraud, Jean-Luc Duval, Corinne Wittmer, Ludovic Gaut, et al.. Poly ( $\epsilon$-caprolactone)/Hydroxyapatite 3D Honeycomb Scaffolds for a Cellular Microenvironment Adapted to Maxillofacial Bone Reconstruction. ACS Biomaterials Science and Engineering, 2018, 4 (9), pp.3317-3326. 10.1021/acsbiomaterials.8b00521 . hal-02393845

\section{HAL Id: hal-02393845 \\ https://hal.sorbonne-universite.fr/hal-02393845}

Submitted on 4 Dec 2019

HAL is a multi-disciplinary open access archive for the deposit and dissemination of scientific research documents, whether they are published or not. The documents may come from teaching and research institutions in France or abroad, or from public or private research centers.
L'archive ouverte pluridisciplinaire HAL, est destinée au dépôt et à la diffusion de documents scientifiques de niveau recherche, publiés ou non, émanant des établissements d'enseignement et de recherche français ou étrangers, des laboratoires publics ou privés. 


\title{
Poly(e-caprolactone)/Hydroxyapatite 3D Honeycomb Scaffolds for a Cellular Microenvironment Adapted to Maxillofacial Bone Reconstruction
}

\author{
Alejandro Garcia Garcia, ${ }^{\dagger}$ Anne Hébraud, ${ }^{\ddagger}$ Jean-Luc Duval, ${ }^{\dagger}$ Corinne R. Wittmer, ${ }^{\ddagger}$ Ludovic Gaut, $^{\S}, \|$ \\ Delphine Duprez, ${ }^{\S, \|}$ Christophe Egles, ${ }^{\dagger}$ Fahmi Bedoui, ${ }^{\perp}$ Guy Schlatter, ${ }^{\ddagger \odot}$ and Cecile Legallais $*, \dagger \odot$ \\ ${ }^{\dagger}$ CNRS, UMR 7338 Laboratory of Biomechanics and Bioengineering, Sorbonne Universités, Université de Technologie de \\ Compiègne, Rue du Dr. Schweitzer, 60200 Compiegne, France \\ ${ }^{\ddagger}$ ICPEES UMR 7515, Institut de Chimie et Procédés pour l'Energie, l’Environnement et la Santé, CNRS, Université de Strasbourg, \\ 25 Rue Becquerel, 67087 Strasbourg, France \\ ${ }^{\S}$ CNRS, UMR 7622, IBPS-Developmental Biology Laboratory, Sorbonne Université, 7-9 Quai Saint Bernard, 75005 Paris, France \\ "Inserm U1156, 7-9 Quai Saint Bernard, 75005 Paris, France \\ ${ }^{\perp}$ Roberval Laboratory for Mechanics, Sorbonne Universités, Université de Technologie de Compiègne, Rue du Dr. Schweitzer, \\ 60200 Compiègne, France
}

Supporting Information

ABSTRACT: The elaboration of biomimetic materials inspired from the specific structure of native bone is one the main goal of tissue engineering approaches. To offer the most appropriate environment for bone reconstruction, we combined electrospinning and electrospraying to elaborate an innovative scaffold composed of alternating layers of polycaprolactone (PCL) and hydroxyapatite (HA). In our approach, the electrospun PCL was shaped into a honeycomb-like structure with an inner diameter of $160 \mu \mathrm{m}$, capable of providing bone cells with a 3D environment while ensuring the material biomechanical strength. After 5 days of culture without any differentiation factor, the murine embryonic cell line demonstrated excellent cell viability on contact with the PCL-HA structures as well as active colonization of the scaffold. The cell differentiation, as tested by RTqPCR, revealed a 6-fold increase in the expression of the RNA of the Bglap involved in bone mineralization as compared to a classical $2 \mathrm{D}$ culture. This
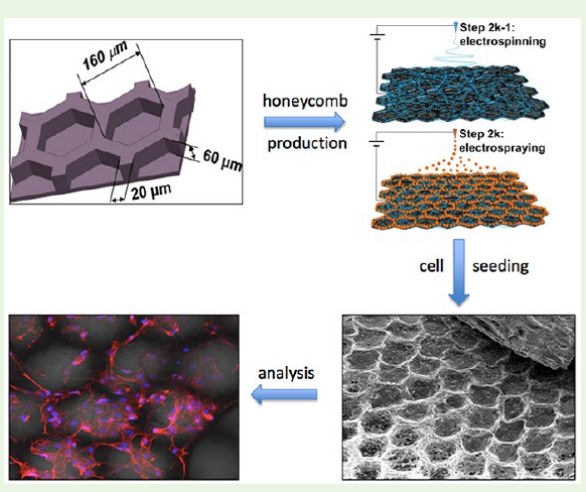

differentiation of the cells into osteoblasts was confirmed by alkaline phosphatase staining of the scaffold cultivated with the cell lineage. Later on, organotypic cultures of embryonic bone tissues showed the high capacity of the PCL-HA honeycomb structure to guide the migration of differentiated bone cells throughout the cavities and the ridge of the biomaterial, with a colonization surface twice as big as that of the control. Taken together, our results indicate that PCL-HA honeycomb structures are biomimetic supports that promotes in vitro osteocompatibility, osteoconduction, and osteoinduction and could be suitable for being used for bone reconstruction in complex situations such as the repair of maxillofacial defects.

KEYWORDS: bone, electrospinning, honeycomb, cell differentiation, biomimetic

\section{INTRODUCTION}

Bone is a hierarchical and complex mineralized connective tissue involved in a continuous remodelling process. ${ }^{1}$ The remodelling cycle is composed of three consecutive phases: (I) resorption of old bone by osteoclasts, (II) transition from resorption to bone formation, and (III) formation of new bone matrix by osteoblasts. ${ }^{2}$ This extracellular matrix is composed of organic components, mainly type I collagen and other inorganic compounds such as calcium phosphates. ${ }^{3,4}$ It is organized in cylindrical units called osteons, which have a diameter of around $200 \mu \mathrm{m}$ in a human adult. There are multiple situations in which bone regeneration is compromised, such as diseases, aging, or major defects, where the bone need reconstruction. ${ }^{5}$ For example, maxillofacial defects are still a surgical challenge ${ }^{6}$ as a result of trauma and disfigurement. ${ }^{7}$ Autologous bone grafts remain the "gold standard"8,9 but are not free of drawbacks such as a high level of postsurgical morbidity or the limited availability and quality of bone. ${ }^{10}$

The use of biomaterials and recent developments in tissue engineering $^{11}$ are promising for complete regeneration of bone defects by combining materials, cells, and growth factors, making possible the creation of a scaffold that resembles native tissue. ${ }^{12}$ Different materials have been proposed over the years

Received: May 3, 2018

Accepted: August 20, 2018

Published: August 20, 2018 
to mimic the organic and porous part in bone tissue based on either bio-organic molecules ${ }^{13-17}$ or on synthetic polymers such as poly $(\varepsilon$-caprolactone $)(\mathrm{PCL}),{ }^{18,19}$ or others. ${ }^{20,21}$ One of the main limitations of organic compounds is their rapid degradation and the lack of mechanical strength, while synthetic polymers suffer from a lack of osteoconduction and osteoinduction, two major requirements for bone healing. ${ }^{22}$ There has thus been interest in recent years in combining these polymers with bioceramics such as tricalcium phosphate (TCP) or hydroxyapatite (HA) to benefit from the inorganic composition inherent to the bone. ${ }^{23-25}$

The structure of the extracellular niche and the 3D organization are also of prime importance. Varied approaches have been deployed to generate scaffolds. These include hydrogel formation, ${ }^{26}$ freeze-drying, ${ }^{27}$ extrusion, ${ }^{28}$ or more recently $3 \mathrm{D}$ printing. ${ }^{29}$ Of these approaches, electrospinning ${ }^{30}$ is one of the most promising techniques for creating a fibrous matrix that mimics the extracellular bone matrix, creating a $3 \mathrm{D}$ environment suitable for the cells. ${ }^{31,32}$ However, although a thin layer of an electrospun material is considered to be very porous, the high packaging density of a scaffold prevents the cells from correct colonization through thick materials. In addition, these structures do not mimic the osteon organization. Very recently, the advantage of using concave areas to stimulate osteoblasts and therefore enhance bone formation was highlighted using a variety of techniques. ${ }^{33-35}$ Composite scaffolds with a controlled 3D microstructure could be obtained using cooperative electrostatic interactions during simultaneous electrospinning and electrospraying on a rotating micropatterned collector. ${ }^{36}$ As an illustration, honeycomb structures were composed of PCL in which nanoparticles of hydroxyapatite were inserted to control the bilayered structure of the cavities. ${ }^{37}$

Therefore, in this study, we proposed the development of new, multilayered scaffolds made of PCL fibers and HA particles with controlled pore size, mimicking the osteon structure, imagined as a honeycomb network. ${ }^{38}$ According to the characterization of its physical and mechanical properties, the colonisation and differentiation in the honeycomb structures were assessed using two approaches: (I) study of the early fate of a mesenchymal stem cell line of mice origin, cultured on the scaffold in the absence of any differentiation factor, and (II) the organotypic culture of bone from chicken embryos, a common biocompatibility test for implantable biomaterials.

\section{MATERIALS AND METHODS}

Fabrication of the Honeycomb Collectors. Honeycomb micropattern collectors were manufactured by means of photolithography. An SU-8 2050 (Microchem) photoresist layer with a thickness of $60 \mu \mathrm{m}$ was deposited over a silicon wafer. The photoresist layer was exposed to UV light through a honeycomb mask using a mask aligner (MJB4, SUSS Microtec). The photoresist layer was then developed and cured to obtain the honeycomb micropatterns. Finally, a Plassys MEB5505 electron beam evaporator was used to deposit a conductive layer (composed of a $120 \mathrm{~nm} \mathrm{Al}$ layer and a $30 \mathrm{~nm} \mathrm{Au} \mathrm{layer)} \mathrm{on} \mathrm{the} \mathrm{collectors.} \mathrm{The} \mathrm{micropatterns}$ covered a square area measuring $44 \mathrm{~mm} \times 44 \mathrm{~mm}$. The internal size of the honeycombs was $160 \mu \mathrm{m}$, the width and height of the honeycomb walls were 20 and $60 \mu \mathrm{m}$, respectively (see Figure 1B).

Scaffold Production by Electrospinning/Electrospraying. A solution of $15 \mathrm{wt} \% \operatorname{poly}\left(\varepsilon\right.$-caprolactone) $\left(\mathrm{PCL}, \mathrm{MW}=80 \mathrm{~kg} \mathrm{~mol}^{-1}\right.$, CAPA 6806, Perstorp) was dissolved in dichloromethane (DCM, Sigma-Aldrich)/N,N-dimethylformamide (DMF, Reagent Plus $\geq 99 \%$,
Sigma-Aldrich) $(60 / 40 \mathrm{v} / \mathrm{v})$ for $24 \mathrm{~h}$ before electrospinning. Then 10 wt $\%$ hydroxyapatite (HA, Sigma-Aldrich, nanopowder with a particle size of $\leq 200 \mathrm{~nm}$ (BET), $\geq 97 \%$ synthetic) suspension was prepared in ethanol (Sigma-Aldrich) $48 \mathrm{~h}$ prior to electrospraying and ultrasonicated for $5 \mathrm{~min}$ (Branson Sonifier) just before processing. Alternating deposition (13 layers, Supporting Information, Table S1) of electrospun PCL layers (distance $15 \mathrm{~cm}$; flow rate $2 \mathrm{~mL} / \mathrm{h}$; needle diameter 18G; voltage $25 \mathrm{kV}$ ) and electrosprayed HA layers (distance $15.5 \mathrm{~cm}$; flow rate $0.6 \mathrm{~mL} / \mathrm{h}$; needle diameter $18 \mathrm{G}$; voltage $25.5 \mathrm{kV}$ ) was performed over a homemade rotating collector. For control, 15\% PCL was electrospun over a flat aluminum foil with the same parameters.

SEM Characterization and Energy Dispersive X-ray Spectroscopy (EDS) Analysis. The morphology and topography of the honeycomb-like scaffolds were observed by scanning electron microscopy (Philips XL30 ESEM-FEG). Electrospun mats were cleaned with ethanol, placed in an ultrasound bath to remove any impurities, and gold coated prior to observation. Hydroxyapatite deposits over the honeycomb-like scaffold were investigated by EDS analysis using the EDS detector present in the microscope. The measurement is based on the energy and intensity distribution of $\mathrm{X}$ ray signals produced by the electron beam striking the surface of the targeted scaffold.

Tensile Testing. The scaffolds modulus was quantified using uniaxial tensile testing. One sample of each scaffold $(n=3)$ was cut up into a stripe measuring $1.0 \mathrm{~cm} \times 3.0 \mathrm{~cm}$, with a thickness of $31 \pm 5$ $\mu \mathrm{m}$. The thickness of the scaffolds was evaluated using a precision dial thickness gauge (Mitutoyo Corporation, Japan). The samples were secured with the metallic grips of the tensile tester (Bose Electroforce 3200 , TA, USA) and stretched at a rate of $0.1 \mathrm{~mm} \mathrm{~s}^{-1}$ using a cell load of $22 \mathrm{~N}$. Modulus was calculated by analysis of the stress-strain curve in the elastic zone. Ultimate strength (UTS) was measured from the highest peak in the stress-strain curve.

Cell Seeding on Scaffolds. The embryonic murine cell line C3H10T1/2 (ATCCCL-226) was cultured on to a Corning T-75 flask at a confluence of $85 \%$ with Dulbecco's Modified Eagle's Medium low-glucose (DMEM; Hyclone, USA) supplemented with $10 \%$ fetal bovine serum (FBS, Gibco Invitrogen, USA), $2 \mathrm{mM}$ glutamine (Gibco Invitrogen, USA), and $1 \%$ of penicillinstreptomycin (Gibco Invitrogen, USA) under standard culture conditions. To evaluate the response of the cells to materials, the scaffolds were cut into squares measuring $17 \mathrm{~mm} \times 17 \mathrm{~mm}$, disinfected with ethanol 70\% (Sigma-Aldrich, USA) for $45 \mathrm{~min}$, and washed with PBS 7.4 (phosphate buffered saline, Gibco Invitrogen, USA) for $10 \mathrm{~min}$ before the cell culture experiment. Each scaffold was plated with a density of $1 \times 10^{5}$ cells $\mathrm{cm}^{-2}$. After 2 days of culture, the culture media were replaced and the culture was prolonged for three additional days.

Cell Viability and Proliferation. After 5 days of culture cell viability was estimated with a Live/Dead kit (Invitrogen, Waltham, MA, USA). Calcein AM (1 mM) and ethidium homodimer-1 (EthD$1,1 \mathrm{mM}$ ) fluorescent dyes were used to stain viable and dead cells, respectively. The samples were observed using fluorescence microscopy (Leica Microsystem, Wetzlar, Germany), allowing us to qualitatively determine cell viability and distribution. Next, cell proliferation was evaluated at different time points $(24,48$, and $96 \mathrm{~h})$ with 3-(4, 5-dimethylthiazol-2yl)-2, 5-diphenyl-2H-tetrazolium bromide (MTT) assay. After different time periods, $2.5 \mathrm{mg} / \mathrm{mL}$ of MTT in complete culture media was added on each well. After $3 \mathrm{~h}$ of incubation, dimethyl sulfoxide (DMSO) was used to dissolve formazan crystals. The absorbance of the solution was measured using a Spark multimode microplate reader (TECAN, Swiss) at a wavelength of $590 \mathrm{~nm}$. SEM (Philips XL30 ESEM-FEG) was used to observe the attachment of the cells to the scaffolds. After 5 days of culture, all the samples were washed twice with PBS, fixed in a solution of Rembaum for $1 \mathrm{~h}$, and then washed twice with permuted water. Each sample was finally gold-coated for SEM observation.

Cell behavior on the scaffold was assessed using rhodamine phalloidin (Invitrogen, USA) to selectively stain the F-actin. The cells were fixed with $4 \%(\mathrm{w} / \mathrm{v})$ paraformaldehyde solution (PAF, Agar 

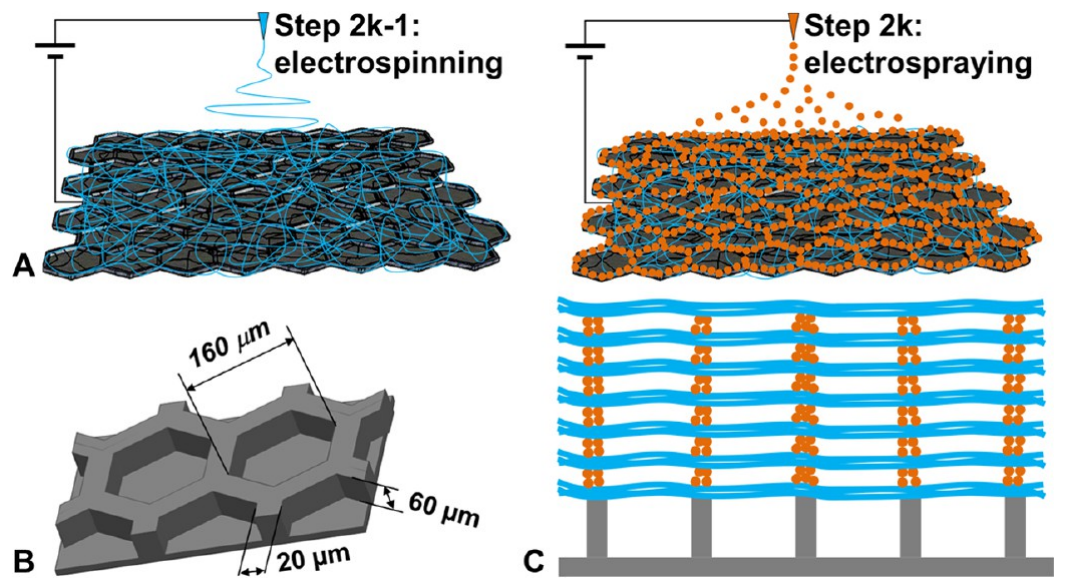

Figure 1. Design of the honeycomb-like scaffolds. (A) Odd steps: electrospinning process. Even steps: electrospraying process. (B) Geometry of the honeycomb collector. (C) Both steps were repeated to achieve the production of a 3D multilayer scaffold with HA microparticles mainly located over the wall of the honeycomb collector thanks to the electrostatic template effect.

Scientific, United Kingdom) in PBS for 10 min then permeabilized with $0.5 \%$ Triton X-100 (VWR, United Kingdom) for $10 \mathrm{~min}$. Nonspecific binding sites were blocked by incubating the substrates in $1 \%(\mathrm{w} / \mathrm{v})$ BSA (Sigma-Aldrich, USA) in PBS for $15 \mathrm{~min}$. The staining solution rhodamine phalloidin was added at $5 \mathrm{U} / \mathrm{mL}$ for $45 \mathrm{~min}$. In addition, Hoechst $33342^{39}$ was added to every experiment. Samples were then washed in PBS and observed with an Inverted ZEISS 710 confocal microscope (Zeiss, Germany) and Leica fluorescence microscopy (Leica Microsystems, Germany).

Gene Expression Analyses. Gene expression was studied using RT-qPCR (reverse transcription quantitative polymerase chain reaction) after 5 days of culture on the scaffolds. Briefly, samples were lysed with $350 \mu \mathrm{L}$ of RLT Buffer (Qiagen, Germany) and centrifuged to extract the RNA (ribonucleic acid) according to the manufacturer's protocol. The RNA was retro-transcribed into DNA (DNA) using a High Capacity cDNA Reverse Transcription Kit (Applied Biosystems, USA) according to the manufacturer's protocol. RT-qPCR was performed using the SYBR Green PCR Master Mix (Applied Biosystems). Relative mRNA levels were calculated using the $2-\Delta \Delta C t$ method. ${ }^{40}$ The $\Delta C t$ s were obtained from $C t$ normalized with the Rplp0 gene levels in each sample. The primers are listed in Supporting Information, Table S2, and reactions were checked before the experiments (efficiency $>80 \%, R^{2}>0.99$ ). The results were compared with data from samples cultured without scaffolds, i.e., data were plotted as a ratio to a cell-only control group, highlighting the intrinsic effect of the scaffolds on the gene expression.

Alkaline Phosphatase (ALP) Activity. ALP activity, an early marker of osteoblast differentiation, was assessed using a quantitative colorimetric Alkaline Phosphatase Assay Kit (Abcam, UK) after 5 days of culture following manufacturer's instruction. In addition, BCIP/NBT (Sigma-Aldrich, USA) solution was used according to the manufacturer's protocol to stain alkaline phosphatase. Areas that stained purple were considered as positive.

Organotypic Culture. Slices of bone from chicken embryos explanted tissue were put over the surface of honeycomb scaffolds $(n$ $=20) \cdot{ }^{41}$ Every sample was cultured over 2 weeks into Dulbecco's Modified Eagle's Medium low-glucose (DMEM; Hyclone, USA) supplemented with $40 \%$ fetal bovine serum (FBS, Gibco Invitrogen, USA), $2 \mathrm{mM}$ glutamine (Gibco Invitrogen, USA), and $0.15 \%$ of penicillin-streptomycin (Gibco Invitrogen, USA) under standard culture condition. After 2 weeks of culture, 16 samples were observed with an Optical Microscopy $(\times 25)$, and four samples were fixed into Rembaum solution for $1 \mathrm{~h}$ and then washed twice with permuted water. Each sample was finally coated with gold for SEM observation.

Statistical Analysis. All data are represented as mean \pm standard deviation (SD). Mann-Whitney nonparametric statistical test was used to define the significance of the results.

\section{RESULTS}

Production and Materials Characterization of Honeycomb-Like Electrospun Scaffold. Honeycomb-like scaffolds were produced by the alternate electrospinning of PCL fiber layers and the electrospraying of HA particle layers over a micropatterned collector as depicted in Figure 1. The mechanisms making microstructuration possible were explained by an electrostatic template effect, which was induced by the fiber portions deposited over the pattern holes during the first step of electrospinning. These portions of fiber, hanging in the air, retained their electric charges, leading to repulsive forces located at precise areas defined by the design of the patterned collector. On the other hand, the portions of fiber in direct contact with the collector patterns were able to dissipate their charges efficiently, thus leading to attractive forces. These repulsive and attractive forces were then able to act after an electrospraying step, resulting in precise deposits of microparticles on the attractive areas thanks to the so-called electrostatic template effect. ${ }^{37}$

We produced the 3D scaffolds with six bilayers (Figure 1): each bilayer consisted of a layer of electrospun PCL fibers with an average fiber diameter of $145 \pm 39 \mathrm{~nm}$ covered by a layer of electrosprayed HA nanoparticles (Figure 1C). A final layer of PCL fibers was deposited in order to encapsulate the last layer of HA microparticles. The final thickness of the scaffold was measured as $31 \pm 5 \mu \mathrm{m}$. The main challenge consisted in maintaining the design of the electrostatic template intact during the various electrospinning and electrospraying steps (Figure 2A-C). Enough particles had to be electrosprayed to ensure efficient electric contact with the collector patterns as shown in the inset of Figure 1B. An electrospinning time of 8 min for each layer of fibers and an electrospraying time of 10 min for each layer of particles were necessary to ensure that the honeycomb patterns were preserved throughout the process. These parameters made possible the formation of a 3D composite scaffold with a honeycomb structure, the walls of which were formed by dense deposits of HA microparticles and PCL fibers, whereas the honeycomb cavity of the collector was covered by only few PCL fibers, thus forming 3D cavities with a diameter of $160 \mu \mathrm{m}$ sparsely filed with PCL fibers (Figure 2D). The HA deposits were verified with EDS analysis, confirming the presence of calcium (Figure 2E,F). 

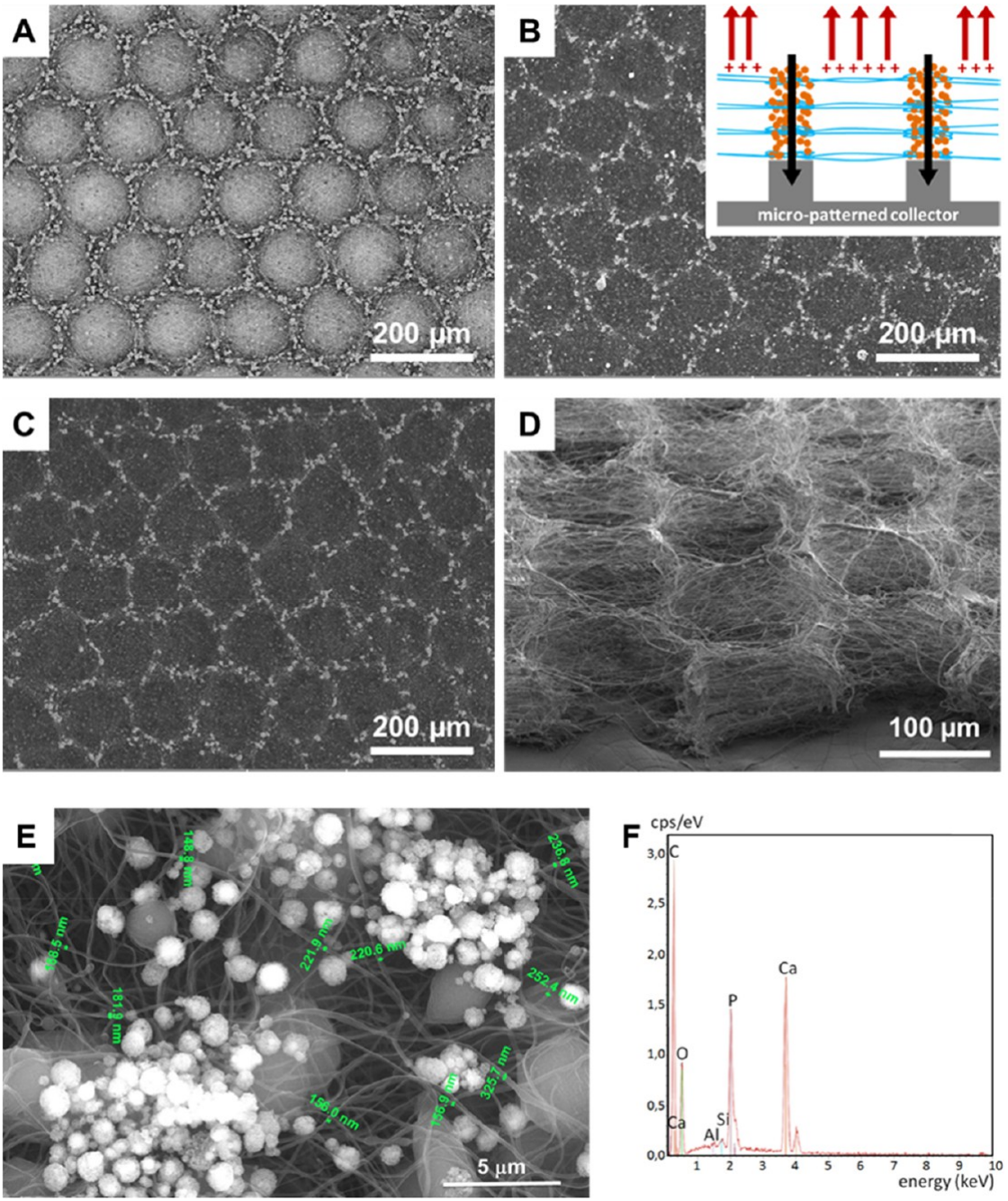

Figure 2. (A-C) SEM images obtained using a backscattered electron detector in order to enhance the contrast between HA and PCL. (A) Top view of a bilayer scaffold obtained from the electrospraying of HA particles over a layer of PCL fibers, which were previously electrospun on to a honeycomb-like micropatterned collector. (B) Top view of a PCL-HA 3D scaffolds obtained from deposits of four bilayers of PCL fibers and HA particles. The inset shows a schematic view of the cross section of this type of scaffold. The black arrows represent the conductive paths formed by the aggregated fibers and particles in contact with the walls of the collector patterns. The red arrows represent the repulsive areas due to the suspended charged fiber segments. (C) Top view of a PCL-HA 3D scaffold obtained from deposits of six bilayers of PCL fibers and HA particles. (D) Cross-section of a PCL-HA 3D scaffold showing the 3D microcavities sparsely filled by PCL fibers. Image obtained with the EverhartThornley detector of SEM. (E) SEM micrographs of the honeycomb-like scaffold for EDS and fiber diameter analysis. (F) EDS spectra of the sample focused over nanoparticles presented on the top of honeycomb wall.

To investigate the strength of the material, uniaxial tension tests were performed on three samples (Figure 3). The
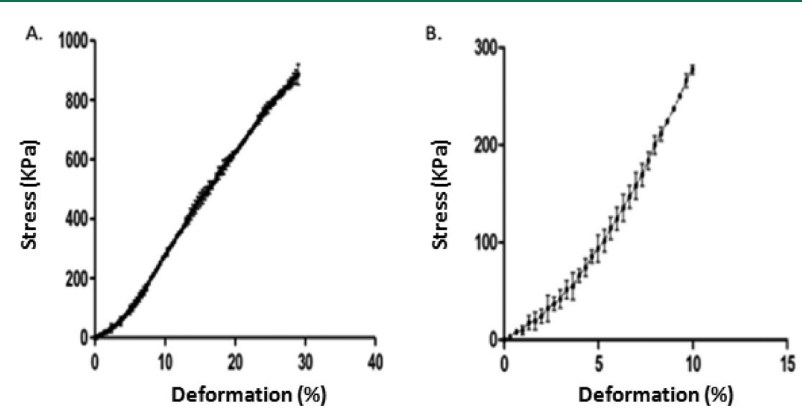

Figure 3. Representative plot of the stress-strain curve of the honeycomb scaffold (with error bars). (A) Ultimate tensile stress (UTS). (B) Linear region where the modulus was calculated from 5 to $10 \%$ strain. displacement velocity was set at $0.1 \mathrm{~mm} \mathrm{~s}^{-1}$ to avoid any damage during the loading phase. Application of Hooke's law led to the calculation of a mean modulus of $3.77 \pm 0.35 \mathrm{MPa}$. The ultimate tensile strength was obtained at $971 \pm 155 \mathrm{kPa}$.

Cells' Viability and Scaffold Colonization. The scaffolds were seeded with $\mathrm{C} 3 \mathrm{H} 10 \mathrm{~T} 1 / 2$ cells at a density of $10^{5}$ cells/ $\mathrm{cm}^{2}$ without any osteogenic factors in order to assess the effect of the scaffold alone. After 5 days of culture, Live/Dead assays were performed to evaluate the cell viability on the polymeric scaffold (Figure 4). The pictures taken under fluorescence microscopy showed excellent cell viability after 5 days of culture with most of living cells in contact with the fibers of the scaffold. MTT assay (Figure 5) indicated that cells cultured on the honeycomb scaffold proliferated, in contrast with TCP where they were probably already at confluence. This is in agreement with the increased available surface offered by the $3 \mathrm{D}$ structure. Indeed, Figure 6 clearly showed that after $2 \mathrm{~h}$, C3H10T1/2 cells still presented a round shape and started to 

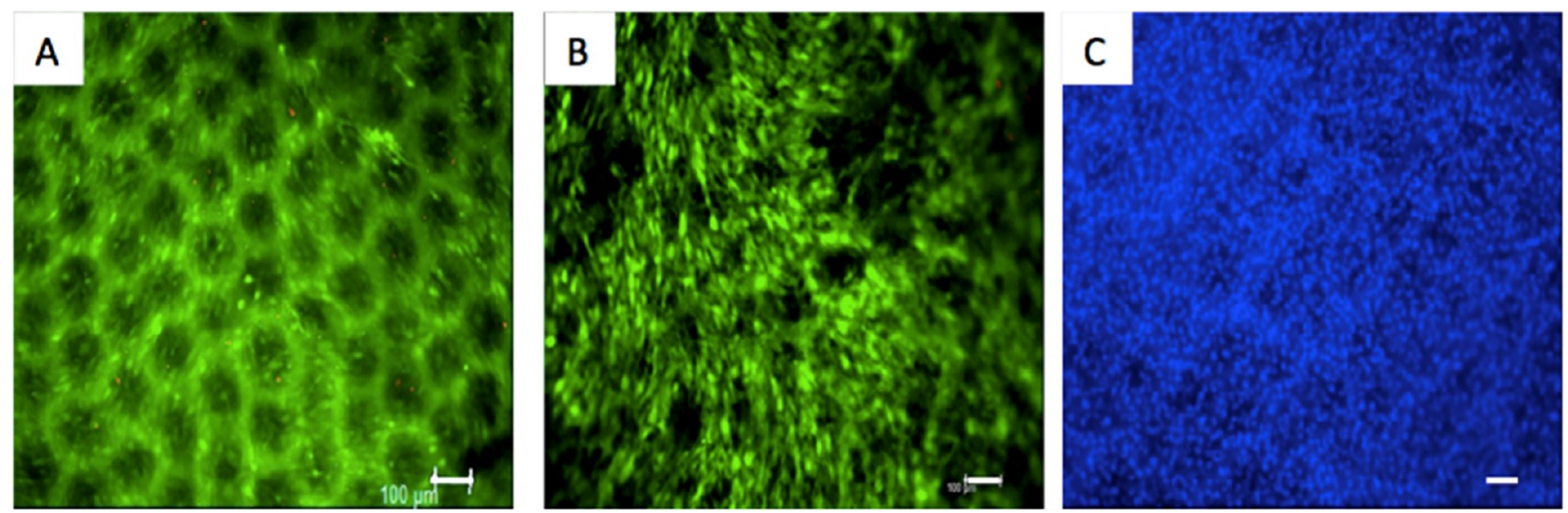

Figure 4. (A-C) C3H10T1/2 viability after 5 days of culture over honeycomb scaffold $(n=3)$. (A) Live and dead stained cells superposed on the honeycomb scaffold. Calcein AM (green) dye shows living cells membranes. EthD-1 dye (red dots) stained the nuclei of dead cells. (B) Live and dead staining on cells. (C) Hoechst 33342 staining all cell nuclei (blue). Scale bar $=100 \mu \mathrm{m}$.

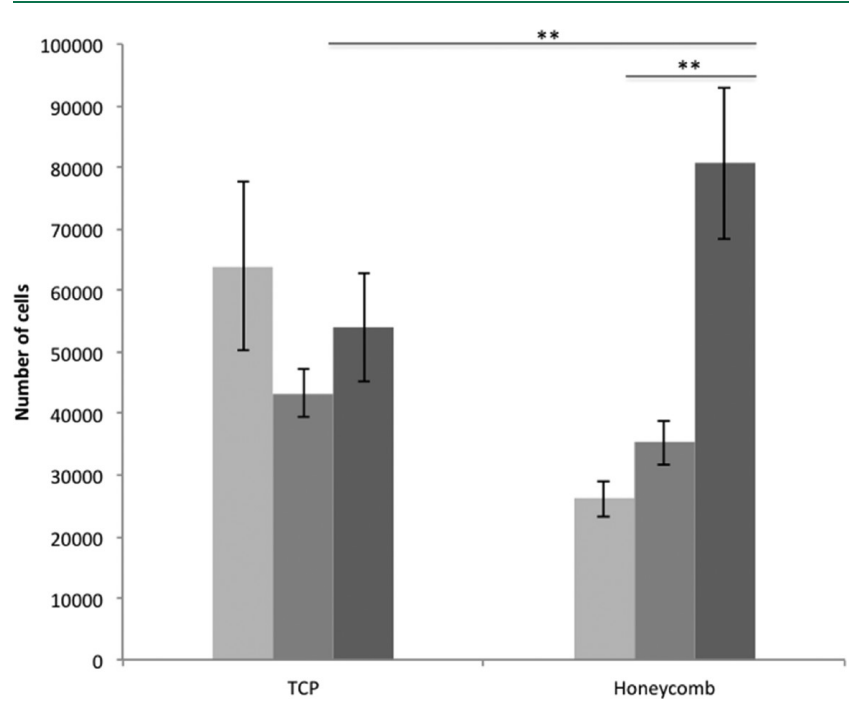

Figure 5. MTT analysis for comparing proliferation of $\mathrm{C} 3 \mathrm{H} 10 \mathrm{~T} 1 / 2$ on honeycomb compared to tissue culture plate (TCP) at D1 (light gray), D2 (medium gray), and D5 (dark gray) $(n=3)$. The data obtained for MTT of the cells cultured on honeycomb-like scaffolds were compared to those of the control cells (tissue culture plate, TCP) with the Mann-Whitney nonparametric statistical test. The $p$ values are indicated for the tests, showing a significant difference between the two groups $(* *$ for $p$-value $=0.0043)$.

adhere on the fibers (Figure 6A). It seems that, at first, the cells preferred to attach to the top of the cavity, spreading along the fibers with an elongated shape (Figure $6 \mathrm{~B}$ ). After $48 \mathrm{~h}$ of culture, the $\mathrm{C} 3 \mathrm{H} 10 \mathrm{~T} 1 / 2$ started to cover the whole depth of the cavity, from the ridge to the bottom (Figure 6C). The cells appeared uniformly distributed without any preference (Figure $6 \mathrm{E}$ and Supporting Information, Figure S1). Taken together, these results show that the cells could cover the entire surface of the cavity.

Cell Differentiation. The preferential differentiation outcomes of $\mathrm{C} 3 \mathrm{H} 10 \mathrm{~T} 1 / 2$ cells cultured in the honeycomb scaffolds were evaluated though the expression of genes of interest by means of RT-qPCR at the end of 5 days of culture. Tendon- and bone-related markers were simultaneously analyzed on the cells cultured in the honeycomb scaffold and control without any differentiation factors to better demonstrate the role of our material and its specific geometry (Figure
7). Runx2, a specific bone transcription factor, ${ }^{42}$ and Bglap a late marker involved in bone mineralization ${ }^{43}$ were used as bone-related genes. To assess to what extent stem cells were committed to the tendon lineage, we used Scx (Scleraxis), a bHLH transcription factor expressed in tendon progenitors and differentiated cells, ${ }^{44}$ and Tnmd (Tenomodulin) a late tendon-specific marker. ${ }^{45}$ The expression of the gene Collal was also analyzed, although we were aware that Collal is expressed in both bone and tendon tissues. The relative mRNA levels of bone and tendon genes in the stem cells cultured on the honeycomb-like scaffold and control conditions led to an increase in Bglap expression (up to 6-fold increase), associated with decreased expression of the $S c x$ tendon-related gene compared to the control plastic cultures, suggesting a shift toward bone differentiation. However, these results must be taken with caution as the late tendon marker Tnmd was also significantly upregulated in cells cultured on the honeycomb scaffold compared to their controls cultured on plastic.

C3H10T1/2 are embryonic cells that are not able to produce ALP in conventional cultures when they are not totally differentiated into osteoblast cells. This enzyme was therefore a suitable marker for investigating cell differentiation because of the intrinsic properties of the honeycomb scaffold. As shown in Figure 8, after 5 days of conventional culture (without any growth factors) in the honeycomb scaffold, high ALP-positive staining (in purple) was found (Figure 8C, indicating changes in phenotype toward osteoblast cells. The negative control without cells showed no staining. In addition, ALP synthesis was quantitatively assessed (Figure 8D) under both culture conditions. ALP activity was found 1.7-fold increased on the honeycomb scaffold. Altogether, these results clearly support the positive effect of the honeycomb scaffolds on cells' differentiation toward bone lineage in the absence of any differentiation factor.

Organotypic Culture. The colonisation by cells originating from bone slices of chicken embryos was observed by scanning electron microscopy and optical microscopy after 14 days of culture. The cells from the explanted tissue spread over a surface of $4.7 \mathrm{~mm}^{2}$ for the control (15\% PCL random) (Figure 9A) and $11 \mathrm{~mm}^{2}$ for the honeycomb scaffolds (Figure 9B). This migration took place over the whole cavity in both the depth and ridge of the honeycomb (Figure 9C,D) with no 

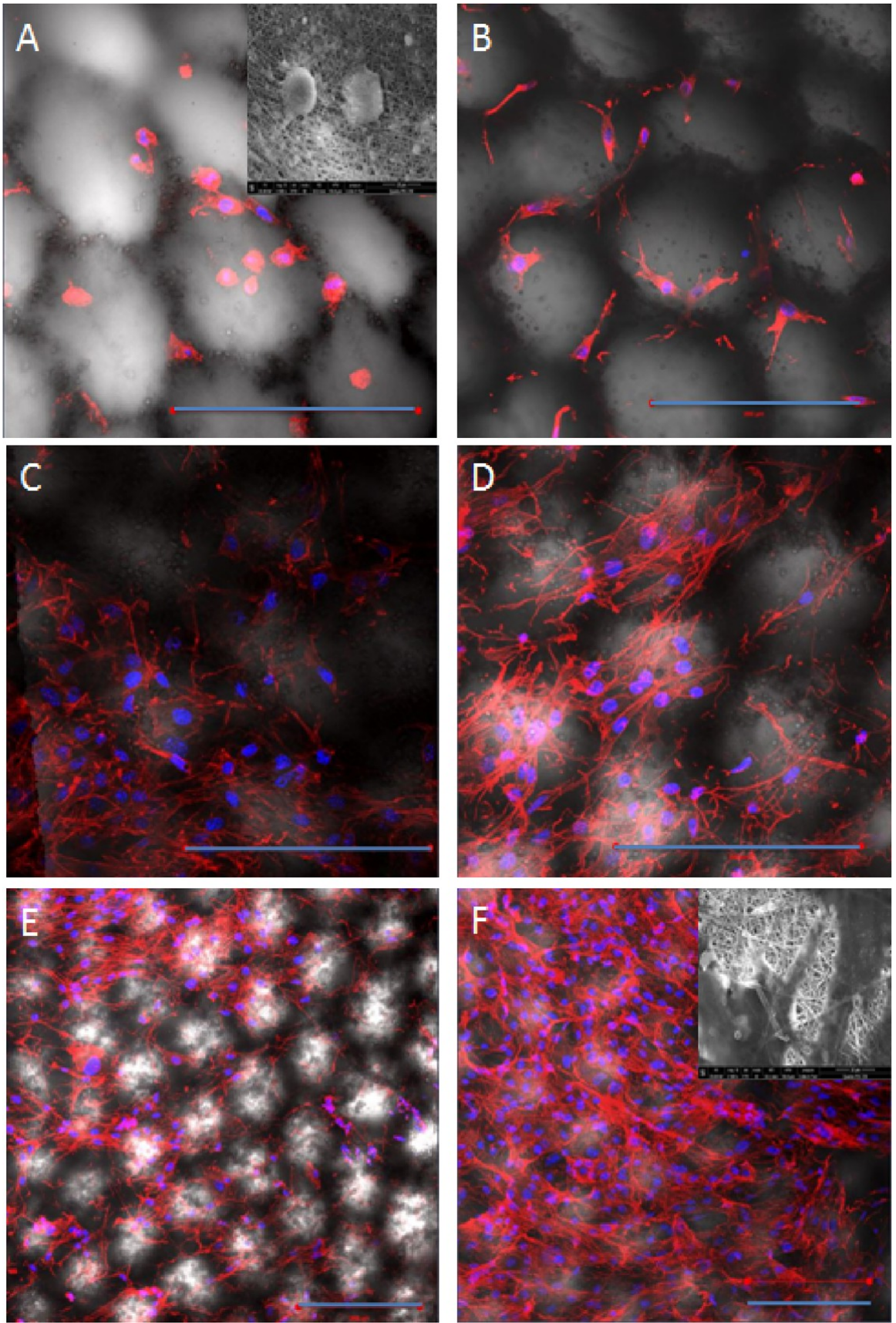

Figure 6. Fluorescence staining of actin cytoskeleton (red) and nuclei (blue) of C3H10T1/2. The cells were cultured for $2 \mathrm{~h}(\mathrm{~A}), 24 \mathrm{~h}(\mathrm{~B}), 48 \mathrm{~h}$ (C), and $96 \mathrm{~h}$ (D) free of growth factors over honeycomb-like scaffolds. Magnification $\times 20$. (E,F) Cells cultured for $48 \mathrm{~h}$ and $96 \mathrm{~h}$, respectively, over the scaffold. Magnification $\times 10$. Scale bars equal $200 \mu \mathrm{m}$. Insert images on (A) and (F) show SEM pictures of adherent cells over the scaffold surface.

preference between regions between the top and bottom of the cavities.

\section{DISCUSSION}

In a previous work, we established the advantages for surgeons of using biomaterials produced as sheets with versatile properties for treating defects in the maxillofacial area. ${ }^{46}$ These sheets are easy to handle and their final shape can be adjusted to fill the defect. In the present study, we demonstrated that the honeycomb structure composed of PCL electrospun fibers and hydroxyapatite nanoparticles is a relevant candidate for a semi-3D organized support for bone regeneration.

Our first goal was to produce such a specific scaffold, adopting a biomimicry approach in order to improve osteinduction. Our hypothesis was that architecture plays an essential role regarding cell response and the mechanical properties of the substitute obtained with respect to the natural tissue to be regenerated. During bone regeneration, osteoclasts dig cavities in the bone and osteoblasts produce new bone. ${ }^{47}$ During this process, osteocytes are formed and remain in the center of a biophysical niche that can be mirrored in our honeycomb architecture. We thus focused on producing a 
Tendon and bone lineage markers expression

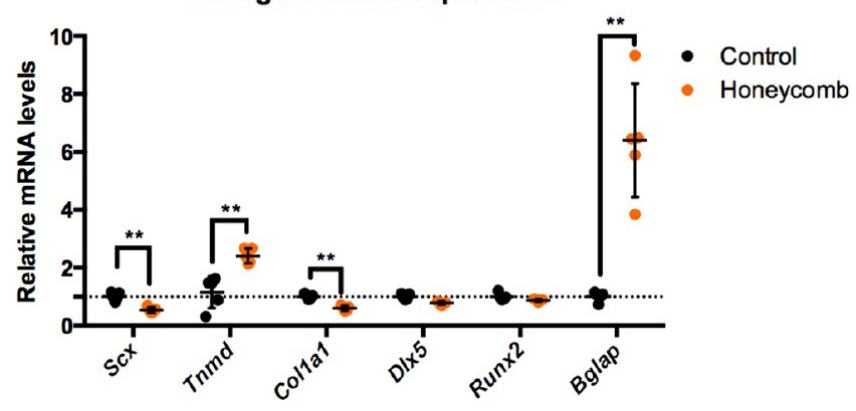

Figure 7. Gene expression of tendon- and bone-related markers in C3H10T1/2 cells cultured on the honeycomb-like scaffolds compared to cells cultured without scaffold. The genes Scx, Tnmd, and Colla1 were uses as tendon markers to assess tenogenic differentiation, although Colla1 is also expressed in bones. Dlx5, Runx2, and Bglap were used as bone markers to assess bone differentiation. The results are displayed as scattered dot plots, each plot representing the result of one sample ( $n=5$ for each condition). The data obtained for gene expression of the cells cultured on honeycomb-like scaffolds (orange dots) were compared to those of the control cells (black dots) with the Mann-Whitney nonparametric statistical test. The $p$-values are indicated for the tests, showing a significant difference between the two groups $(* *$ for $p$-value $=0.0079)$. scaffold mimicking this structure in order to evaluate the relationship between specific morphology properties. It has already been demonstrated that electrospun PCL fibers using template-assisted technique leads to the generation of specific patterns. ${ }^{48}$ In previous studies, honeycomb 3D composite micropatterned scaffolds have already been prepared with poly(lactic acid) fibers and PCL particles ${ }^{36}$ as well as bilayer micropatterned scaffolds with one layer of hydroxyapatite nanoparticles covering electrospun PCL fibers for lab-on-chip applications. ${ }^{37}$ In the present work, we demonstrated the feasibility of electrospraying several layers of hydroxyapatite between PCL layers during the process. We were thus able to develop more complex, three-dimensional structures of greater magnitude and, at the same time, mimicking the morphology and composition of the mineral component present in bone.

The final scaffold presented an overall thickness of around $30 \mu \mathrm{m}$ in accordance with previously developed sheets. ${ }^{46}$ The originality of the scaffold also relied on the presence of honeycomb pores (of around $160 \mu \mathrm{m}$ diameter) corresponding to domains sparsely filled by the electrospun fibers. This pore size has been described by many authors as being optimal for promoting cell colonization and bone formation. ${ }^{49-54}$ The Young modulus was very low $(3.77 \pm 0.35 \mathrm{MPa})$ compared to classical scaffolds dedicated to bone regeneration (a range of
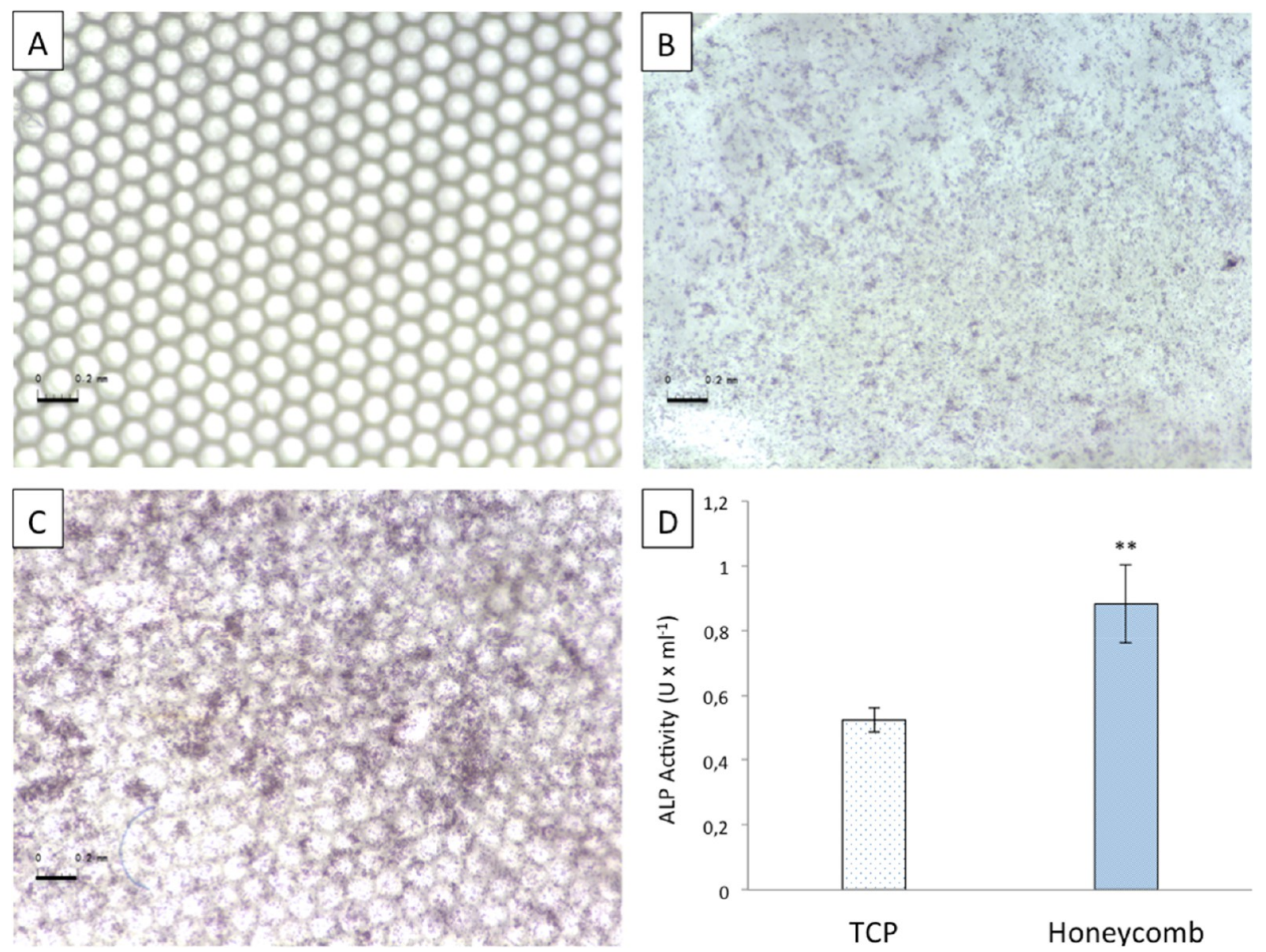

Figure 8. (A-C) Alkaline phosphatase staining on the honeycomb-like scaffold after 5 days of culture. (A) Control honeycomb-like scaffold without cells. (B) C3H10T1/2 cells on culture into TCP control. (C) C3H10T1/2 cells on culture into honeycomb-like scaffold. (D) Alkaline phosphatase activity. The data obtained for alkaline phosphatase activity of the cells cultured on the honeycomb-like scaffolds (blue bar) were compared to those of the control cells cultured on TCP (white bar) with the Mann-Whitney nonparametric statistical test. The $p$-values are indicated for the test, showing a significant difference between the two groups $(* *$ for $p$-value $=0.0043$ ). 

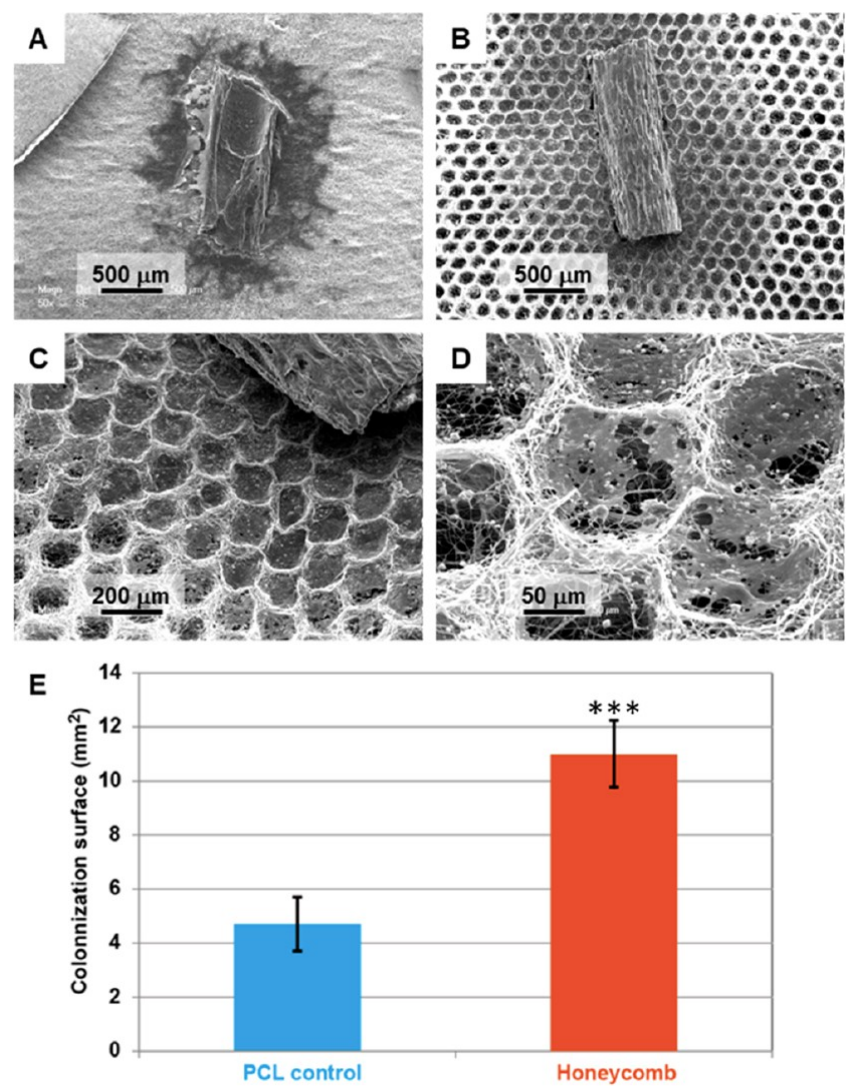

Figure 9. Scanning electron micrographs of honeycomb electrospun scaffold. (A) A 15\% polycaprolactone scaffold being colonized by cells from slices of chicken embryos after 14 days. Scale bar $=500 \mu \mathrm{m}$. (BD) represent the scaffold after being colonized by cells from slices of chicken embryos after 14 days. Scale bar $=500,200$, and $50 \mu \mathrm{m}$, respectively. (E) Migration surface calculated by correlating cell surface in pixels to $\mathrm{mm}^{2}$. The data obtained for cell migration of the cells cultured on the honeycomb-like scaffolds (orange bar) were compared to those of the control cells cultured on $\operatorname{poly}(\varepsilon-$ caprolactone) (blue bar) with the Mann-Whitney nonparametric statistical test. The $p$-values are indicated for the test, showing a significant difference between the two groups (*** for $p$-value $<0.0001)$.

hundreds MPa or more). This can be explained by the facts that the scaffolds are poorly dense in fibers. However, such a mechanical property was intended to allow easy manipulation and changes in shape, as already stated in Baudequin. ${ }^{46}$

To assess the impact of such architecture on the fate of cells, the scaffolds were then seeded with mouse pluripotent stem cells: $\mathrm{C} 3 \mathrm{H} 10 \mathrm{~T} 1 / 2$. This cell line was chosen for its maintained capacity to differentiate into different tissues such as bone, cartilage, adipose tissue, etc. ${ }^{55,56}$ Shea $^{57}$ demonstrated that BMP2 treatment of $\mathrm{C} 3 \mathrm{H} 10 \mathrm{~T} 1 / 2$ mesenchymal stem cells induces both chondrogenesis and osteogenesis. Takata ${ }^{58}$ used them to evaluate the potential of a specific ketone found in raspberries to promote osteogenesis. In the present study, it should be specified that the $\mathrm{C} 3 \mathrm{H} 10 \mathrm{~T} 1 / 2$ were seeded on the scaffold in the absence of any differentiation factor to avoid any guided differentiation toward bone lineage that could be only to the result of the presence of BMP2. The cell behavior observed in our experiments was thus expected to be strictly induced by cell-material interactions.

In contact with the 3D honeycomb scaffold, and after 5 days of culture, the cells presented high viability over the entire surface, both in the center of the cavity and in the ridges. We demonstrated that cells arranged themselves according to the shape of the support: they were elongated on the ridges and spread randomly across the width at the bottom of the cavity. Cells were thus able to colonise the whole material, as shown by the proliferation assay, and take advantage of the added surface provided by $3 \mathrm{D}$ shapes and the support of the electrospun fibers.

The increase in expression of characteristic bone genes, such as Bglap, showed clear differentiation toward the osteoblastic lineage. This finding was corroborated by the clear ALP production and staining observed on the cell-seeded scaffolds. This osteoinduction may be attributed to the combined effect of the presence of hydroxyapatite nanoparticles and of the specific morphology of the scaffold. Gomez-Lizarraga ${ }^{59}$ demonstrated that electrospun PCL combined with HA nanoparticles promoted cell viability and proliferation. To deeply analyze the role of the honeycomb structure alone, it would be interesting to compare the outcomes with those of the same scaffold devoid of HA. However, the production of such scaffold with the present method is not possible because HA electrospraying is mandatory to perform layer by layer production of the $3 \mathrm{D}$ structure.

Tenomodulin also appeared to increase with respect to the control; this increase might be due to regions located at the top of the cavity, with straight fibers that could promote cell differentiation into tendon lineage. BMSCs were shown to differentiate toward the tendon lineage when the support on which they grew presented an alignment. ${ }^{60}$

Finally, thanks to the organotypic study, we demonstrated that differentiated cells present in the bones of chicken embryos were able to leave and colonize the honeycomb structure. The surface on which cells spread was larger on this support than on a simple support composed of PCL 15\%. This shows the potential of this scaffold for osteoconduction, which is a major advantage in case of surgical implantation.

\section{CONCLUSION}

In this study, we succeeded in producing a biomimetic scaffold with the relevant properties of osteocompatibility, osteoconduction, and osteoinduction. Successive layers of electrospun PCL and electrosprayed HA nanoparticles on a collector equipped with hexagonal micropatterns led to the production of a scaffold with an overall shape of a sheet but with a 3D honeycomb structure. In this scaffold, mesenchymal stem cells showed a preference for early differentiation toward bone lineage in the absence of any differentiation factors. These results are very promising for exploiting this material in bone reconstruction either in vitro as tissue engineering approaches or directly in vivo as a regenerative supporting biomaterial.

\section{ASSOCIATED CONTENT}

\section{S Supporting Information}

The Supporting Information is available free of charge on the ACS Publications website at DOI: 10.1021/acsbiomaterials.8b00521.

Electrospinning and electrospraying parameters step by step; solution A, PCL at $15 \% \mathrm{~W} / \mathrm{V}$ in DCM/DMF 60/ $40 \%$; solution $\mathrm{B}, \mathrm{HA}$ at $10 \% \mathrm{~W} / \mathrm{V}$ in ethanol; list of primers used for RT-qPCR; C3H10T1/2 colonization over a honeycomb groove (PDF) 
Confocal stack of cells over a honeycomb groove; honeycomb scaffold in gray (white light); cell cytoskeleton in red (Phalloidin-Rhodamine); cell nuclei in blue (Hoechst 3342) (AVI)

\section{AUTHOR INFORMATION}

\section{Corresponding Author}

*Tel.: +33-344234670. E-mail: cecile.legallais@utc.fr.

\section{ORCID $\odot$}

Anne Hébraud: 0000-0002-6018-1523

Guy Schlatter: 0000-0003-3037-4129

Cecile Legallais: 0000-0002-8061-906X

Notes

The authors declare no competing financial interest.

\section{ACKNOWLEDGMENTS}

This work was carried out and funded in the framework of the Labex MS2T. It was supported by the French Government, through the program "Investments for the future" managed by the National Agency for Research (reference ANR-11-IDEX0004-02) and by Région Hauts de France (INTIM project). A. Hebraud, C. Wittmer, and G. Schlatter also thank the financial support of the project ANR MimHeart (ANR-15-CE08-0010) and Sabine Siegwald for the fabrication of the micropatterned collectors at the clean room STnano (Strasbourg, France).

\section{REFERENCES}

(1) Buck, D. W.; Dumanian, G. A. Bone Biology and Physiology: Part I. The Fundamentals. Plast. Reconstr. Surg. 2012, 129 (6), 13141320.

(2) Reznikov, N.; Shahar, R.; Weiner, S. Bone Hierarchical Structure in Three Dimensions. Acta Biomater. 2014, 10 (9), 3815-3826.

(3) Alford, A. I.; Kozloff, K. M.; Hankenson, K. D. Extracellular Matrix Networks in Bone Remodeling. Int. J. Biochem. Cell Biol. 2015, $65,20-31$.

(4) Chai, Y. C.; Carlier, A.; Bolander, J.; Roberts, S. J.; Geris, L.; Schrooten, J.; Van Oosterwyck, H.; Luyten, F. P. Current Views on Calcium Phosphate Osteogenicity and the Translation into Effective Bone Regeneration Strategies. Acta Biomater. 2012, 8 (11), 38763887.

(5) Amini, A. R.; Laurencin, C. T.; Nukavarapu, S. P. Bone Tissue Engineering: Recent Advances and Challenges. Crit. Rev. Biomed. Eng. 2012, 40 (5), 363-408.

(6) Rai, R.; Raval, R.; Khandeparker, R. V.; Chidrawar, S. K.; Khan, A. A.; Ganpat, M. S. Tissue Engineering: Step Ahead in Maxillofacial Reconstruction. J. Int. Oral Health JIOH 2015, 7 (9), 138-142.

(7) Glynn, S. M.; Shetty, V.; Elliot-Brown, K.; Leathers, R.; Belin, T. R.; Wang, J. Chronic Posttraumatic Stress Disorder after Facial Injury: A 1-Year Prospective Cohort Study. J. Trauma 2007, 62 (2), 410418.

(8) Kretlow, J. D.; Young, S.; Klouda, L.; Wong, M.; Mikos, A. G. Injectable Biomaterials for Regenerating Complex Craniofacial Tissues. Adv. Mater. 2009, 21 (32-33), 3368-3393.

(9) Moura, L. B.; Carvalho, P. H. de A.; Xavier, C. B.; Post, L. K.; Torriani, M. A.; Santagata, M.; Chagas Júnior, O. L. Autogenous NonVascularized Bone Graft in Segmental Mandibular Reconstruction: A Systematic Review. Int. J. Oral Maxillofac. Surg. 2016, 45 (11), 13881394.

(10) LaPrade, R. F.; Botker, J. C. Donor-Site Morbidity after Osteochondral Autograft Transfer Procedures. Arthrosc. J. Arthrosc. Relat. Surg. Off. Publ. Arthrosc. Assoc. N. Am. Int. Arthrosc. Assoc. 2004, 20 (7), e69-73.

(11) Seidi, A.; Ramalingam, M.; Elloumi-Hannachi, I.; Ostrovidov, S.; Khademhosseini, A. Gradient Biomaterials for Soft-to-Hard Interface Tissue Engineering. Acta Biomater. 2011, 7 (4), 1441-1451.
(12) Fernandez-Yague, M. A.; Abbah, S. A.; McNamara, L.; Zeugolis, D. I.; Pandit, A.; Biggs, M. J. Biomimetic Approaches in Bone Tissue Engineering: Integrating Biological and Physicomechanical Strategies. Adv. Drug Delivery Rev. 2015, 84, 1-29.

(13) Glowacki, J.; Mizuno, S. Collagen Scaffolds for Tissue Engineering. Biopolymers 2008, 89 (5), 338-344.

(14) Dawson, J. I.; Wahl, D. A.; Lanham, S. A.; Kanczler, J. M.; Czernuszka, J. T.; Oreffo, R. O. Development of Specific Collagen Scaffolds to Support the Osteogenic and Chondrogenic Differentiation of Human Bone Marrow Stromal Cells. Biomaterials 2008, 29 (21), 3105-3116.

(15) Oh, B. H. L.; Bismarck, A.; Chan-Park, M. B. Injectable, Interconnected, High-Porosity Macroporous Biocompatible Gelatin Scaffolds Made by Surfactant-Free Emulsion Templating. Macromol. Rapid Commun. 2015, 36 (4), 364-372.

(16) Saravanan, S.; Leena, R. S.; Selvamurugan, N. Chitosan Based Biocomposite Scaffolds for Bone Tissue Engineering. Int. J. Biol. Macromol. 2016, 93, 1354-1365.

(17) Venkatesan, J.; Bhatnagar, I.; Manivasagan, P.; Kang, K.-H.; Kim, S.-K. Alginate Composites for Bone Tissue Engineering: A Review. Int. J. Biol. Macromol. 2015, 72, 269-281.

(18) Xue, R.; Qian, Y.; Li, L.; Yao, G.; Yang, L.; Sun, Y. Polycaprolactone Nanofiber Scaffold Enhances the Osteogenic Differentiation Potency of Various Human Tissue-Derived Mesenchymal Stem Cells. Stem Cell Res. Ther. 2017, 8, 148.

(19) Xu, T.; Miszuk, J. M.; Zhao, Y.; Sun, H.; Fong, H. Electrospun Polycaprolactone 3D Nanofibrous Scaffold with Interconnected and Hierarchically Structured Pores for Bone Tissue Engineering. Adv. Healthcare Mater. 2015, 4 (15), 2238-2246.

(20) Guduric, V.; Metz, C.; Siadous, R.; Bareille, R.; Levato, R.; Engel, E.; Fricain, J.-C.; Devillard, R.; Luzanin, O.; Catros, S. Layerby-Layer Bioassembly of Cellularized Polylactic Acid Porous Membranes for Bone Tissue Engineering. J. Mater. Sci.: Mater. Med. 2017, 28 (5), 78.

(21) Chen, Y.; Xu, J.; Huang, Z.; Yu, M.; Zhang, Y.; Chen, H.; Ma, Z.; Liao, H.; Hu, J. An Innovative Approach for Enhancing Bone Defect Healing Using PLGA Scaffolds Seeded with ExtracorporealShock-Wave-Treated Bone Marrow Mesenchymal Stem Cells (BMSCs). Sci. Rep. 2017, 7, 44130.

(22) Albrektsson, T.; Johansson, C. Osteoinduction, Osteoconduction and Osseointegration. Eur. Spine J. 2001, 10, S96-S101.

(23) Lao, L.; Wang, Y.; Zhu, Y.; Zhang, Y.; Gao, C. Poly(LactideCo-Glycolide)/Hydroxyapatite Nanofibrous Scaffolds Fabricated by Electrospinning for Bone Tissue Engineering. J. Mater. Sci.: Mater. Med. 2011, 22 (8), 1873-1884.

(24) Wongsupa, N.; Nuntanaranont, T.; Kamolmattayakul, S.; Thuaksuban, N. Assessment of Bone Regeneration of a TissueEngineered Bone Complex Using Human Dental Pulp Stem Cells/ Poly $(\varepsilon$-Caprolactone)-Biphasic Calcium Phosphate Scaffold Constructs in Rabbit Calvarial Defects. J. Mater. Sci.: Mater. Med. 2017, 28 (5), 77.

(25) Huang, J.; Lin, Y. W.; Fu, X. W.; Best, S. M.; Brooks, R. A.; Rushton, N.; Bonfield, W. Development of Nano-Sized Hydroxyapatite Reinforced Composites for Tissue Engineering Scaffolds. J. Mater. Sci.: Mater. Med. 2007, 18 (11), 2151-2157.

(26) Xu, C.; Su, P.; Chen, X.; Meng, Y.; Yu, W.; Xiang, A. P.; Wang, Y. Biocompatibility and Osteogenesis of Biomimetic BioglassCollagen-Phosphatidylserine Composite Scaffolds for Bone Tissue Engineering. Biomaterials 2011, 32 (4), 1051-1058.

(27) Shimizu, H.; Jinno, Y.; Ayukawa, Y.; Atsuta, I.; Arahira, T.; Todo, M.; Koyano, K. Tissue Reaction to a Novel Bone Substitute Material Fabricated With Biodegradable Polymer-Calcium Phosphate Nanoparticle Composite. Implant Dent 2016, 25 (5), 567-574.

(28) Shor, L.; Güçeri, S.; Chang, R.; Gordon, J.; Kang, Q.; Hartsock, L.; An, Y.; Sun, W. Precision Extruding Deposition (PED) Fabrication of Polycaprolactone (PCL) Scaffolds for Bone Tissue Engineering. Biofabrication 2009, 1 (1), 015003.

(29) Bendtsen, S. T.; Quinnell, S. P.; Wei, M. Development of a Novel Alginate-Polyvinyl Alcohol-Hydroxyapatite Hydrogel for 3D 
Bioprinting Bone Tissue Engineered Scaffolds. J. Biomed. Mater. Res., Part A 2017, 105 (5), 1457-1468.

(30) Sankar, S.; Sharma, C. S.; Rath, S. N.; Ramakrishna, S. Electrospun Nanofibres to Mimic Natural Hierarchical Structure of Tissues: Application in Musculoskeletal Regeneration. J. Tissue Eng. Regener. Med. 2018, 12, e604-e619.

(31) Kishan, A. P.; Cosgriff-Hernandez, E. M. Recent Advancements in Electrospinning Design for Tissue Engineering Applications: A Review. J. Biomed. Mater. Res., Part A 2017, 105 (10), 2892-2905.

(32) Wu, Y.; Dong, Z.; Wilson, S.; Clark, R. Template-Assisted Assembly of Electrospun Fibers. Polymer 2010, 51, 3244.

(33) Ripamonti, U. Biomimetism, Biomimetic Matrices and the Induction of Bone Formation. J. Cell. Mol. Med. 2009, 13 (9B), 29532972.

(34) Graziano, A.; d'Aquino, R.; Cusella-De Angelis, M. G.; De Francesco, F.; Giordano, A.; Laino, G.; Piattelli, A.; Traini, T.; De Rosa, A.; Papaccio, G. Scaffold's Surface Geometry Significantly Affects Human Stem Cell Bone Tissue Engineering. J. Cell. Physiol. 2008, 214 (1), 166-172.

(35) Takabatake, K.; Yamachika, E.; Tsujigiwa, H.; Takeda, Y.; Kimura, M.; Takagi, S.; Nagatsuka, H.; Iida, S. Effect of Geometry and Microstructure of Honeycomb TCP Scaffolds on Bone Regeneration. J. Biomed. Mater. Res., Part A 2014, 102 (9), 2952-2960.

(36) Wittmer, C. R.; Hébraud, A.; Nedjari, S.; Schlatter, G. WellOrganized 3D Nanofibrous Composite Constructs Using Cooperative Effects between Electrospinning and Electrospraying. Polymer 2014, 55 (22), 5781-5787.

(37) Nedjari, S.; Hébraud, A.; Eap, S.; Siegwald, S.; Mélart, C.; Benkirane-Jessel, N.; Schlatter, G. Electrostatic Template-Assisted Deposition of Microparticles on Electrospun Nanofibers: Towards Microstructured Functional Biochips for Screening Applications. RSC $A d v$. 2015, 5 (102), 83600-83607.

(38) Clarke, B. Normal Bone Anatomy and Physiology. Clin. J. Am. Soc. Nephrol. 2008, 3, S131-S139.

(39) Smolewski, P.; Bedner, E.; Gorczyca, W.; Darzynkiewicz, Z. Liquidless" Cell Staining by Dye Diffusion from Gels and Analysis by Laser Scanning Cytometry: Potential Application at Microgravity Conditions in Space. Cytometry 2001, 44 (4), 355-360.

(40) Livak, K. J.; Schmittgen, T. D. Analysis of Relative Gene Expression Data Using Real-Time Quantitative PCR and the 2(-Delta Delta C(T)) Method. Methods 2001, 25 (4), 402-408.

(41) Duval, J.-L.; Dinis, T.; Vidal, G.; Vigneron, P.; Kaplan, D. L.; Egles, C. Organotypic Culture to Assess Cell Adhesion, Growth and Alignment of Different Organs on Silk Fibroin. J. Tissue Eng. Regener. Med. 2017, 11 (2), 354-361.

(42) Komori, T. Regulation of Osteoblast Differentiation by Runx2. Adv. Exp. Med. Biol. 2009, 658, 43-49.

(43) Lee, N. K.; Sowa, H.; Hinoi, E.; Ferron, M.; Ahn, J. D.; Confavreux, C.; Dacquin, R.; Mee, P. J.; McKee, M. D.; Jung, D. Y.; et al. Endocrine Regulation of Energy Metabolism by the Skeleton. Cell 2007, 130 (3), 456-469.

(44) Schweitzer, R.; Chyung, J. H.; Murtaugh, L. C.; Brent, A. E.; Rosen, V.; Olson, E. N.; Lassar, A.; Tabin, C. J. Analysis of the Tendon Cell Fate Using Scleraxis, a Specific Marker for Tendons and Ligaments. Development 2001, 128 (19), 3855-3866.

(45) Shukunami, C.; Takimoto, A.; Oro, M.; Hiraki, Y. Scleraxis Positively Regulates the Expression of Tenomodulin, a Differentiation Marker of Tenocytes. Dev. Biol. 2006, 298 (1), 234-247.

(46) Baudequin, T.; Bedoui, F.; Dufresne, M.; Paullier, P.; Legallais, C. Towards the Development and Characterization of an Easy Handling Sheet-like Biohybrid Bone Substitute. Tissue Eng., Part A 2015, 21 (11-12), 1895-1905.

(47) Parfitt, A. M. Osteonal and Hemi-Osteonal Remodeling: The Spatial and Temporal Framework for Signal Traffic in Adult Human Bone. J. Cell. Biochem. 1994, 55 (3), 273-286.

(48) Wu, H.; Fan, J.; Chu, C.-C.; Wu, J. Electrospinning of Small Diameter 3-D Nanofibrous Tubular Scaffolds with Controllable Nanofiber Orientations for Vascular Grafts. J. Mater. Sci.: Mater. Med. 2010, 21 (12), 3207-3215.
(49) Borden, M.; El-Amin, S. F.; Attawia, M.; Laurencin, C. T. Structural and Human Cellular Assessment of a Novel MicrosphereBased Tissue Engineered Scaffold for Bone Repair. Biomaterials 2003, 24, 597-609.

(50) Götz, H. E.; Müller, M.; Emmel, A.; Holzwarth, U.; Erben, R. G.; Stangl, R. Effect of Surface Finish on the Osseointegration of Laser-Treated Titanium Alloy Implants. Biomaterials 2004, 25 (18), 4057-4064.

(51) Jin, Q. M.; Takita, H.; Kohgo, T.; Atsumi, K.; Itoh, H.; Kuboki, Y. Effects of Geometry of Hydroxyapatite as a Cell Substratum in BMP-Induced Ectopic Bone Formation. J. Biomed. Mater. Res. 2000, 51 (3), 491-499.

(52) Mankani, M. H.; Kuznetsov, S. A.; Fowler, B.; Kingman, A.; Gehron Robey, P. G. In Vivo Bone Formation by Human Bone Marrow Stromal Cells: Effect of Carrier Particle Size and Shape. Biotechnol. Bioeng. 2001, 72, 96-107.

(53) Jones, A. C.; Arns, C. H.; Hutmacher, D. W.; Milthorpe, B. K.; Sheppard, A. P.; Knackstedt, M. A. The Correlation of Pore Morphology, Interconnectivity and Physical Properties of 3D Ceramic Scaffolds with Bone Ingrowth. Biomaterials 2009, 30 (7), 1440-1451.

(54) Bigerelle, M.; Giljean, S.; Anselme, K. Existence of a Typical Threshold in the Response of Human Mesenchymal Stem Cells to a Peak and Valley Topography. Acta Biomater. 2011, 7 (9), 3302-3311.

(55) Date, T.; Doiguchi, Y.; Nobuta, M.; Shindo, H. Bone Morphogenetic Protein-2 Induces Differentiation of Multipotent C3H10T1/2 Cells into Osteoblasts, Chondrocytes, and Adipocytes in Vivo and in Vitro. J. Orthop. Sci. 2004, 9 (5), 503-508.

(56) Baudequin, T.; Gaut, L.; Mueller, M.; Huepkes, A.; Glasmacher, B.; Duprez, D.; Bedoui, F.; Legallais, C. The Osteogenic and Tenogenic Differentiation Potential of C3H10T1/2 (Mesenchymal Stem Cell Model) Cultured on PCL/PLA Electrospun Scaffolds in the Absence of Specific Differentiation Medium. Materials 2017, 10, 1387

(57) Shea, C. M.; Edgar, C. M.; Einhorn, T. A.; Gerstenfeld, L. C. BMP Treatment of C3H10T1/2 Mesenchymal Stem Cells Induces Both Chondrogenesis and Osteogenesis. J. Cell. Biochem. 2003, 90 (6), 1112-1127.

(58) Takata, T.; Morimoto, C. Raspberry Ketone Promotes the Differentiation of C3H10T1/2 Stem Cells into Osteoblasts. J. Med. Food 2014, 17 (3), 332-338.

(59) Gómez-Lizárraga, K. K.; Flores-Morales, C.; Del Prado-Audelo, M. L.; Álvarez-Pérez, M. A.; Piña-Barba, M. C.; Escobedo, C. Polycaprolactone- and Polycaprolactone/Ceramic-Based 3D-Bioplotted Porous Scaffolds for Bone Regeneration: A Comparative Study. Mater. Sci. Eng., C 2017, 79, 326-335.

(60) Subramony, S. D.; Dargis, B. R.; Castillo, M.; Azeloglu, E. U.; Tracey, M. S.; Su, A.; Lu, H. H. The Guidance of Stem Cell Differentiation by Substrate Alignment and Mechanical Stimulation. Biomaterials 2013, 34 (8), 1942-1953. 